\title{
Circadian Variation of Topoisomerase II- $\alpha$ in Human Rectal Crypt Epithelium: Implications for Reduction of Toxicity of Chemotherapy
}

Frederic Clayton, M.D., Kathryn A. Tessnow, M.D., John C. Fang, M.D., Joseph A. Holden, M.D., John G. Moore, M.D.

Department of Pathology (FC) and Gastroenterology Division (JGM), Salt Lake Veterans Administration Hospital, Salt Lake City, Utah, and Gastroenterology Division (KAT, JCF, JGM) and Pathology Department (FC, JAH), University of Utah

Topoisomerase II-alpha is a target of common chemotherapeutic agents such as doxorubicin and etoposide, which induce DNA damage by altering the activity of this enzyme. We took rectal biopsies at 4-hour intervals over a 24-hour period (seven total) from each of 10 healthy volunteers and examined immunoperoxidase-stained coded antitopoisomerase II-alpha-stained sections. A significant circadian periodicity was seen in the number of rectal crypt epithelial cell nuclei that were stained $(P=.01)$. Mean peak staining was at 7:23 a.m. \pm 45 minutes, and the mean rate of change (difference between peak and trough expression) was $40 \%$. Topoisomerase II-alpha expression in rectal epithelium has a significant circadian variation similar to that of tritiated thymidine incorporation. Although direct confirmation is needed, giving topoisomerase II-targeted chemotherapeutic agents at the proper time of day might reduce their mucositis side effects.

KEY WORDS: Adverse effects, Circadian rhythm, Colon, DNA topoisomerase II, Doxorubicin, Drug therapy, Etoposide, Rectum.

Mod Pathol 2002;15(11):1191-1196

Circadian rhythms of DNA synthesis and cell proliferation have been documented in human epidermal (1-3), buccal (4), and rectal epithelia $(5,6)$, and in bone marrow $(7,8)$. These human studies, and $>30$ experimental studies in lower animals, have been used to design protocols for time-qualified

Copyright $(\odot) 2002$ by The United States and Canadian Academy of Pathology, Inc.

VOL. 15, NO. 11, P. 1191, 2002 Printed in the U.S.A.

Date of acceptance: July 20, 2002.

Address reprint requests to: Frederic Clayton, M.D., Pathology Department, Salt Lake Veterans Administration Hospital, 500 Foothill Drive, Salt Lake City, UT 84148; e-mail: drfclayton@aol.com; fax: 801-584-1297.

DOI: 10.1097/01.MP.0000032529.68297.B2 delivery of chemotherapeutic agents to tumorbearing animals and to cancer patients $(9,10)$. In two prospective randomized clinical trials, in patients with metastatic colorectal cancer, time- of-day-modified 5-fluouracil, leucovorin and oxaliplatin-based chemotherapy significantly $(P<.00001)$ reduced the incidence of severe mucositis (from 76 to $14 \%$ ) and significantly $(P=.003$ ) improved the objective response rate (from 29 to $51 \%$ ), compared with a flatrate infusion schedule $(11,12)$. In a third multicenter study, an intensified chronomodulated course of these agents led to an objective response rate of $66 \%$ (13). This salutary circadian modified clinical response could be due to circadian variation in nontumor tissue proliferative activity-chemotherapyinduced damage probably would be greatest at the peak time of DNA synthesis (S phase) or mitosis.

DNA topoisomerases link and unlink DNA strands, allowing DNA to twist or untwist as it becomes coiled or uncoiled (14). Topoisomerase IIalpha (topo II- $\alpha$ ) is involved in chromosomal condensation and segregation and is essential for untangling intertwined DNA molecules before mitosis (15-17). Topo II- $\alpha$ is needed as cells synthesize new DNA and then separate their newly made chromosomes. The enzyme is synthesized in late G1 and early S-phase, is present in the cell during G2 and in $\mathrm{M}$, and then is degraded as the cell enters G1 (18, 19). Several widely used classes of chemotherapeutic agents, including anthracyclines such as doxorubicin and podophyllotoxins such as etoposide, alter topo II- $\alpha$ and thus induce DNA strand breaks $(20,21)$. There is in vitro evidence that topo IItargeted drugs show a pronounced S-phase toxicity (22). Although there is a single murine study presenting evidence of a circadian variation in both toxicity and activity of topoisomerase I (23), to our knowledge there is no prior evidence of a circadian variation in topo II, either in humans or experimental animals. 
The purpose of this study was to determine whether a circadian, or 24-hour, rhythm of topo II- $\alpha$ expression could be detected in healthy human rectal mucosa. Characterizing this rhythm could lead to safer administration of chemotherapeutic agents using topo II- $\alpha$.

\section{MATERIALS AND METHODS}

Ten 24-hour studies were done on 10 healthy male volunteers, aged $18-27$ years (median $=20 \mathrm{y}$ ). Subjects denied any history of significant past or current gastrointestinal disease or surgery. The study was approved by the institutional review board of the Department of Veterans Affairs Salt Lake City Health Care System and the University of Utah. Subjects were not allowed to take medications or ingest alcohol for 48 hours before or during the study. Tobacco use was not allowed during the study. Subjects were fasted from solid foods for 12 hours before the study period and during the 24hour study, except for ad libitum tap water and four Coca Colas (total caloric value $=640 \mathrm{Kcal}$ ) spaced evenly over the 24 hours. All subjects followed their usual day-night sleep schedule, sleeping between 10:30 p.m. and 6:30 a.m., except when awakened for study procedures. All studies were begun at 6 p.m. on Friday and completed at 6 p.m. on Saturday. Biopsy specimens of rectal mucosa were obtained at 4-hour intervals over each 24-hour study (total of seven samples each). No enemas or other bowel preparation were used. An average of six mucosal biopsies were obtained at each time point using standard-sized disposable biopsy forceps through a flexible sigmoidoscope. All biopsies were taken between 5 and $15 \mathrm{~cm}$ from the anal verge. The biopsy specimens for study were immediately placed in neutral buffered formalin. The formalin bottles were coded so that the pathologist (FC) interpreting the slides was blinded as to the timing sequence.
Four biopsies per time point were fixed in neutral buffered formalin and paraffin embedded. Six $4-\mu \mathrm{m}$ sections per slide were cut. The slides underwent diethanolamine-based pressure cooker antigen retrieval with Trilogy (Cell Marque, Austin, TX) using the manufacturer's procedure. After treatment with $0.03 \%$ hydrogen peroxide for 10 minutes, the slides were incubated with mouse monoclonal antitopoisomerase II- $\alpha$ (7 $\mu \mathrm{g} / \mathrm{mL}$ for $20 \mathrm{~min} ; 24)$, and DAKO Envision secondary antibody (20 min), all at $37^{\circ} \mathrm{C}$. The slides were stained with diaminobenzidine and counterstained with hematoxylin. The number of staining nuclei per crypt were counted. Only properly oriented crypts in which the lower two thirds of the crypts were present and not tangentially cut were evaluated. A mean of 13.5 crypts was counted per time point. Two subjects each had one excluded data point because of a lack of welloriented crypts; the other eight subjects had all seven data points.

\section{Statistical Analysis}

The data from all subjects were included in the analysis. All data from all time points except two, as mentioned above, were included (Table 1). To normalize the data, each raw data series for each individual, and for the group $(n=10)$, was analyzed for a circadian rhythm by the least-squares fit of a 24-hour cosine; group rhythm characteristics were summarized by population-mean cosinor values $(25,26)$. The rhythm characteristics include the mesor (middle value of the fitted cosine; the rhythm adjusted mean value), the amplitude (half the difference between the minimum and maximum values of the fitted cosine function), and the high point or acrophase (time of peak value in the fitted cosine function). The standard error (SE) and 95\% confidence interval (CI) estimates were also computed. A $P$ value for the rejection of the zero-amplitude (no

TABLE 1. Topo II-Alpha Expressed as Stained Cells/Crypt

\begin{tabular}{|c|c|c|c|c|c|c|c|c|c|c|c|c|c|c|c|c|}
\hline \multirow{3}{*}{ Subject No. } & \multicolumn{16}{|c|}{ Time (24-h Clock) } \\
\hline & \multicolumn{2}{|c|}{$18: 00 \%$ of } & \multicolumn{2}{|c|}{$22: 00 \%$ of } & \multicolumn{2}{|c|}{$2: 00 \%$ of } & \multicolumn{2}{|c|}{$6: 00 \%$ of } & \multicolumn{2}{|c|}{$10: 00 \%$ of } & \multicolumn{2}{|c|}{$14: 00 \%$ of } & \multicolumn{2}{|c|}{$18: 00 \%$ of } & \multicolumn{2}{|c|}{ All Times } \\
\hline & Raw & Mean & Raw & Mean & Raw & Mean & Raw & Mean & Raw & Mean & Raw & Mean & Raw & Mean & Mean & SEM \\
\hline 1 & 4.31 & 89.9 & 3.75 & 78.2 & 4.69 & 97.8 & 5.17 & 107.8 & 4.77 & 99.5 & 5.54 & 115.6 & 5.33 & 111.2 & 4.79 & 0.25 \\
\hline 2 & 2.88 & 85.5 & 2.67 & 79.2 & 3.23 & 95.8 & 4.27 & 126.7 & 3.33 & 98.8 & 3.71 & 110.1 & 3.50 & 103.9 & 3.37 & 0.22 \\
\hline 3 & 3.86 & 77.1 & 4.43 & 88.4 & 4.93 & 98.4 & 6.61 & 132.0 & 5.20 & 103.8 & 5.20 & 103.8 & 4.83 & 96.4 & 5.01 & 0.35 \\
\hline 4 & 2.79 & 92.3 & 2.67 & 88.3 & 3.61 & 119.4 & 3.29 & 108.8 & 3.88 & 128.4 & 2.69 & 89.0 & 2.23 & 73.8 & 3.02 & 0.24 \\
\hline 5 & 3.50 & 95.1 & 2.25 & 61.1 & 3.21 & 87.2 & 4.00 & 108.7 & 3.58 & 97.2 & 4.17 & 113.3 & 5.06 & 137.4 & 3.68 & 0.36 \\
\hline 6 & 5.40 & 79.1 & 5.61 & 82.2 & 7.00 & 102.5 & 8.00 & 117.2 & 8.85 & 129.6 & ND & $\mathrm{ND}$ & 6.10 & 89.4 & 6.83 & 0.62 \\
\hline 7 & 4.50 & 86.8 & 4.60 & 88.7 & 7.45 & 143.7 & 6.00 & 115.7 & ND & ND & 4.16 & 80.2 & 4.40 & 84.9 & 5.19 & 0.58 \\
\hline 8 & 2.69 & 73.1 & 2.15 & 58.4 & 4.25 & 115.5 & 5.87 & 159.5 & 5.45 & 148.1 & 1.91 & 51.9 & 3.44 & 93.5 & 3.68 & 0.64 \\
\hline 9 & 3.30 & 71.1 & 4.19 & 90.3 & 5.25 & 113.1 & 6.86 & 147.8 & 4.85 & 104.5 & 4.36 & 94.0 & 3.67 & 79.1 & 4.64 & 0.48 \\
\hline 10 & 3.83 & 84.9 & 4.62 & 102.4 & 3.92 & 86.9 & 5.00 & 100.8 & 6.93 & 153.6 & 3.83 & 84.9 & 3.46 & 76.7 & 4.51 & 0.49 \\
\hline Mean & 3.71 & 83.5 & 3.69 & 81.7 & 4.75 & 106.0 & 5.51 & 123.5 & 5.20 & 118.2 & 3.95 & 93.6 & 4.20 & 94.6 & 4.47 & \\
\hline SEM & 0.29 & 2.70 & 0.40 & 4.48 & 0.49 & 5.77 & 0.48 & 6.00 & 0.62 & 7.84 & 0.40 & 7.14 & 0.38 & 6.40 & 0.37 & \\
\hline
\end{tabular}

ND, inadequate tissue sample. 


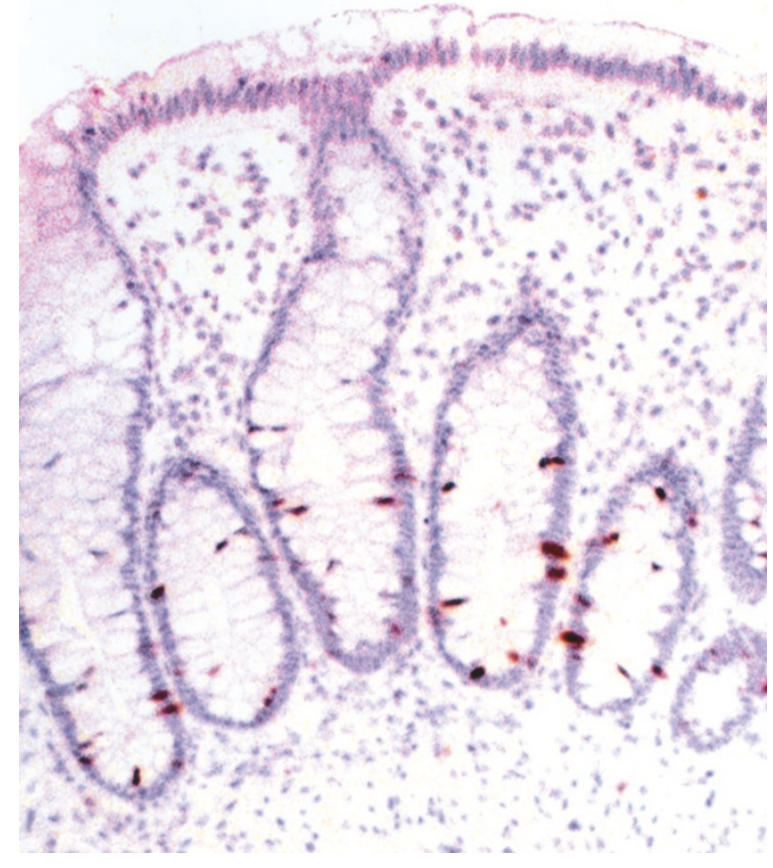

FIGURE 1. Immunostaining for topoisomerase II- $\alpha$ in rectal crypts at highest time point (6 a.m.), showing about 5.4 staining nuclei per crypt.

rhythm) assumption was determined for each individual series and for the group. Rhythm detection is considered statistically significant when $P \leq .05$. The range of change between high and low raw and normalized values was also calculated and subjected to paired $t$-test analysis.

\section{RESULTS}

Similar to the case in a prior study (27), topo II- $\alpha$ staining was found in epithelial cell nuclei in the bottom one-third to one-half of the crypts (Figs. 1, 2). There was no significant epithelial cell staining in the superficial portions of the crypts or surface epithelium. There were more cells staining in the crypts in the morning samples (Fig. 1) than in the evening ones (Fig. 2). The stained cells per crypt data (expressed in number of topo II- $\alpha$-stained nuclei per rectal crypt) and rate of change values are listed in Table 1 and graphed in Figure 3. The mean rate of change (lowest to highest value) was $40 \%$ ( $P$ $=.000375)$.

The cosinor rhythm analysis of the raw and normalized data for each individual, and for the group, is tabulated in Table 2. The rhythm plots are shown in Figure 3. A significant circadian rhythm in nuclear topo II- $\alpha$ expression in rectal crypt mucosa was found in both the raw $(P=.02)$ and normalized $(P=.01)$ values. The amplitude of the normalized data curve was $19.43 \%$. The time of peak value (acrophase) of the normalized group data series was calculated at 07:23 a.m. \pm 45 minutes. Analysis

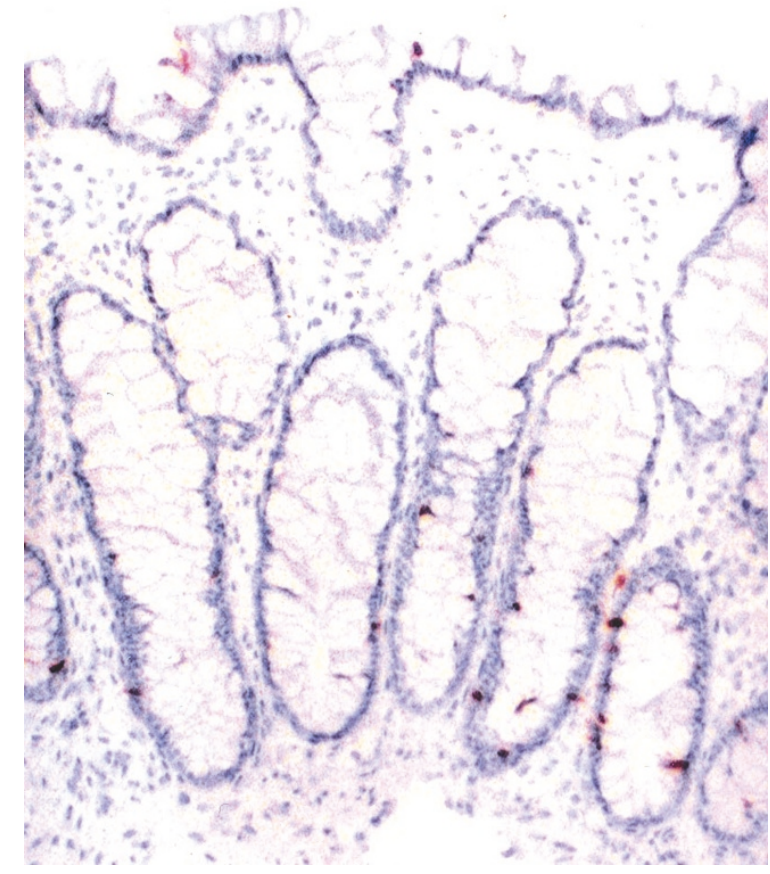

FIGURE 2. Immunostaining for topoisomerase II- $\alpha$ in rectal crypts at a low time point (6 p.m.) showing about 3.4 staining nuclei per crypt.

of the data for each subject showed acrophase values varying from 03:41 a.m. to 1:00 p.m.

\section{DISCUSSION}

These data show a significant rhythm in topo II- $\alpha$ nuclear staining of rectal crypt cells in healthy male subjects. The acrophase, or time of highest value, occurred at 07:23 a.m., near the end of the sleep phase in the usual sleep-wake schedule. Although the acrophase did vary among the different subjects, it does appear that topo II- $\alpha$ expression is least in the early evening.

The 7:23 a.m. acrophase for topo II- $\alpha$ staining is near the acrophase value of 07:04 a.m. of incorporation of tritiated thymidine $\left({ }^{[3 \mathrm{H}]} \mathrm{TdR}\right)$ into rectal tissue biopsy samples obtained over the circadian period in a study reported from our institution (5) using very similar study conditions. Although the uptake of ${ }^{[3 \mathrm{H}]} \mathrm{TdR}$ may not be precisely synonymous with DNA synthesis (28), the correspondence in acrophase values in the two studies, employing different markers, support the view that both are markers of cellular proliferation. In another human rectal biopsy study, using ${ }^{[3 \mathrm{H}]} \mathrm{TdR}$ radioautography techniques, a circadian rhythm in ${ }^{[3 \mathrm{H}]} \mathrm{TdR}$ labeling was found in the basal cells of rectal crypts with an acrophase value of 01:28 a.m. (6). The lack of precise agreement in acrophase values between the two ${ }^{[3 \mathrm{H}]}$ TdR-based circadian rectal biopsy studies may relate to the different ${ }^{[3 \mathrm{H}]} \mathrm{TdR}$ techniques employed in the two studies and the limitations of 


\section{Topoisomerase II - Alpha in Rectal Epithelia}
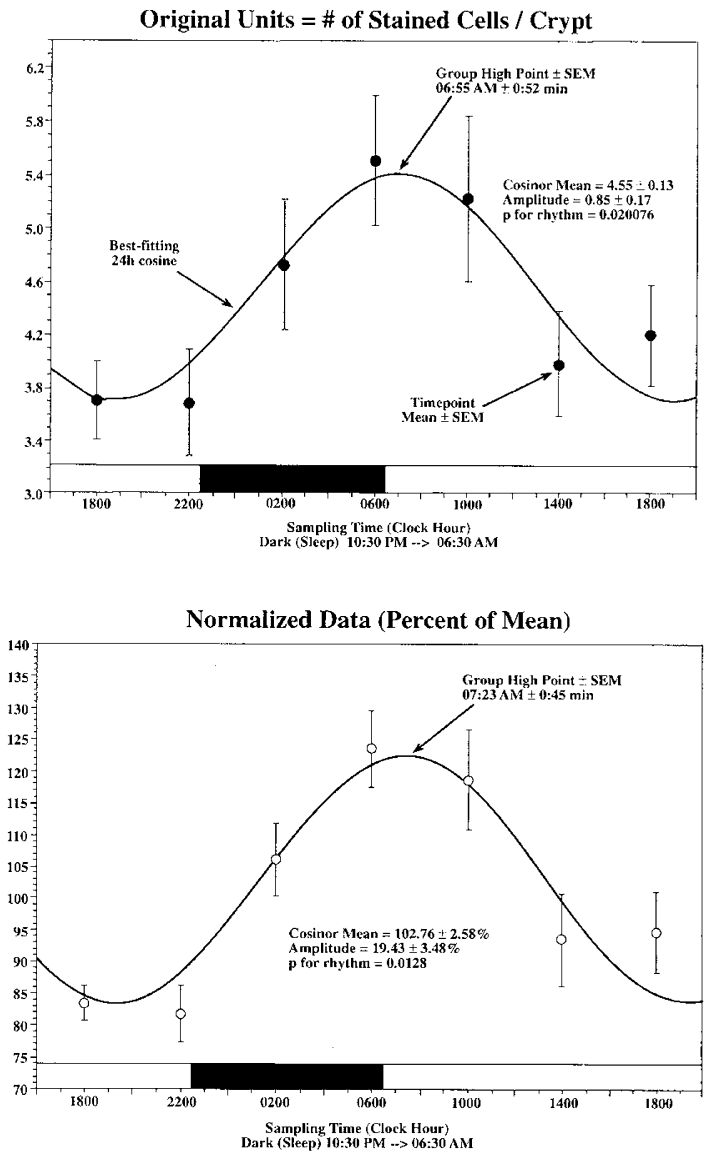

FIGURE 3. Circadian expression of topoisomerase II- $\alpha$ in rectal crypts of 10 healthy men. Values expressed in raw numbers of mean stained cells per crypt in the upper curve and normalized as a percentage of the 24-hour rhythm adjusted mean in the lower curve. Each point represents the mean \pm the standard error of the mean. Al times are local clock time.
${ }^{[3 \mathrm{H}]} \mathrm{TdR}$ incorporation techniques in general (28). Bjarnason et al. $(4,29)$ recently reported significant circadian variation in the expression of cell-cycle and cellular clock proteins and thymidylate synthase activity (an S-phase indicator) in human oral (buccal) epithelium but did not study topoisomerase. These studies suggested an S-phase acrophase in early afternoon. Scheving et al. (30) showed, in rodent gut, significant circadian variation in ${ }^{[3 \mathrm{H}]} \mathrm{TdR}$ incorporation in mucosal epithelia throughout the entire gastrointestinal tract. Although the phasing of the rhythms in different regions of the gastrointestinal tract was fairly similar, the acrophase for tongue epithelium preceded that of colonic epithelium by about 3 hours. Ohdo et al. (23) studied topoisomerase I activity and the toxicity of a topo I-targeted agent. In mice, they found that bone marrow topo I activity, as well as the greatest weight loss from the topo I-targeted agent, irinotecan, occurred near the end of the active cycle or early in the rest cycle, a time also matching the greatest $\mathrm{S}$-phase fraction.

To our knowledge, this is the first evidence for a circadian variation in topo II- $\alpha$ expression. This finding may have implications for cancer chemotherapy. Although there was significant variation in the timing of the acrophase among our subjects, it appears that topo II- $\alpha$ expression is generally least in the early evening. Topoisomerase-mediated damage is most extensive in S phase (22). As previously mentioned, tritiated thymidine incorporation, an S-phase marker, had a very similar acrophase in a prior study from our institution under similar conditions (5). Thus, early evening, when both S-phase fraction and topo II- $\alpha$ expression are minimal, should be the best time to administer the relevant chemotherapeutic agents to minimize mucositis toxicity. However, direct confirmation of this is needed.

TABLE 2. Circadian Parameters for Topo II-Alpha Nuclear Expression: Raw and Normalized Data for Each Subject

\begin{tabular}{|c|c|c|c|c|c|c|c|c|}
\hline \multirow[b]{2}{*}{ Subject No. } & \multicolumn{4}{|c|}{ Raw Data } & \multicolumn{4}{|c|}{ Normalized Data } \\
\hline & $\begin{array}{c}\text { Stained cells, } \\
\text { No./Crypt } \\
\text { (Mean } \pm \text { SEM) }\end{array}$ & $\mathrm{Amp} \pm \mathrm{SEM}$ & $\begin{array}{l}\text { Acrophase } \\
\text { (Peak Time) } \\
\quad \pm \text { SEM }\end{array}$ & $P$ Value & Mean \pm SEM & $\mathrm{Amp} \pm \mathrm{SEM}$ & Acrophase \pm SEM & $P$ Value \\
\hline 1 & $4.81 \pm 0.23$ & $0.55 \pm 0.34$ & $11: 15 \pm 2: 06$ & 0.37 & $100.3 \pm 4.8$ & $11.48 \pm 7.11$ & $11: 50 \pm 2: 06$ & 0.37 \\
\hline 2 & $3.42 \pm 0.18$ & $0.48 \pm 0.26$ & $08: 52 \pm 2: 03$ & 0.28 & $101.5 \pm 5.4$ & $14.25 \pm 7.62$ & $08: 53 \pm 2: 03$ & 0.28 \\
\hline 3 & $5.13 \pm 0.23$ & $0.88 \pm 0.31$ & $07: 20 \pm 1: 29$ & 0.11 & $102.3 \pm 4.6$ & $17.51 \pm 6.21$ & $07: 19 \pm 1: 29$ & 0.11 \\
\hline 4 & $3.11 \pm 0.15$ & $0.62 \pm 0.20$ & $06: 31 \pm 1: 23$ & 0.09 & $102.9 \pm 5.0$ & $20.41 \pm 6.59$ & $06: 31 \pm 1: 23$ & 0.09 \\
\hline 5 & $3.66 \pm 0.34$ & $0.69 \pm 0.51$ & $13: 00 \pm 2: 31$ & 0.47 & $99.3 \pm 6.2$ & $18.61 \pm 13.74$ & $13: 00 \pm 2: 31$ & 0.47 \\
\hline 6 & $7.08 \pm 0.17$ & $1.62 \pm 0.22$ & $08: 37 \pm 0: 32$ & 0.01 & $103.7 \pm 2.4$ & $23.85 \pm 3.22$ & $08: 38 \pm 0: 32$ & 0.01 \\
\hline 7 & $5.35 \pm 0.35$ & $1.34 \pm 0.53$ & $03: 41 \pm 1: 36$ & 0.10 & $103.2 \pm 6.8$ & $25.90 \pm 10.25$ & $03: 41 \pm 1: 36$ & 0.10 \\
\hline 8 & $3.91 \pm 0.41$ & $1.64 \pm 0.54$ & $06: 38 \pm 1: 24$ & 0.09 & $106.3 \pm 11.0$ & $44.60 \pm 14.64$ & $06: 38 \pm 1: 24$ & 0.09 \\
\hline 9 & $4.84 \pm 0.20$ & $1.83 \pm 0.26$ & $05: 48 \pm 0: 49$ & 0.02 & $104.2 \pm 4.3$ & $29.65 \pm 5.63$ & $05: 48 \pm 0: 49$ & 0.02 \\
\hline 10 & $4.64 \pm 0.40$ & $1.20 \pm 0.55$ & $08: 23 \pm 1: 59$ & 0.25 & $102.8 \pm 8.8$ & $24.26 \pm 12.14$ & $08: 23 \pm 1: 59$ & 0.25 \\
\hline Group mean \pm SEM & $4.55 \pm 0.13$ & $0.85 \pm 0.17$ & $06: 55 \pm 0: 52$ & 0.02 & $102.8 \pm 2.6$ & $19.43 \pm 3.48$ & $07: 23 \pm 0: 45$ & 0.01 \\
\hline
\end{tabular}

Acrophase data are in time of day on a 24-hour clock. Amp, amplitude; SEM, standard error of the mean. 
However, the timing of the maximal amount of topo II- $\alpha$ and S phase in normal tissues is but one of several considerations in optimizing the timing and dosage of chemotherapy. Some tumors might also have circadian rhythms (which could be different than the normal tissues), and metabolism and/or clearance of these agents could also vary during the day. Doxorubicin is the only topo II agent whose efficacy has been extensively studied in humans on a circadian basis. Alone or in combination with other agents, doxorubicin has been found to be least toxic and potentially best when given in the early morning (31-33). This could be because, in humans, doxorubucin clearance is fastest in the morning (34), whereas the related drug epirubicin has slower clearance in the morning (35), and etoposide clearance has no diurnal variation (36).

In mice and rats, the early studies found that intraperitoneal doxorubicin is less toxic when given in the early active phase $(37,38)$. However, the optimal timing varies with the route of administration (intraperitoneal versus intravenous; 39). A recent murine study found that intravenous doxorubicin was least toxic in the midrest phase, and, in combination with docetaxel and in consideration of a diurnal variation in efficacy, doses at either the beginning of the rest phase or early in the activity phase were optimal (40). For daunorubicin (41), THP-doxorubicin $(42,43)$, and epirubicin $(44)$, the toxicity is least in the early rest phase, whereas etoposide toxicity is least in the late rest phase (45). Thus, in rodent models, all four anthracycline drugs tested (but not etoposide) were least toxic in the early to mid rest phase, fairly similar to our findings in human rectum.

In summary, we found a significant circadian variation in staining for topo II- $\alpha$ staining in the rectal epithelium of healthy subjects, with the acrophase (peak staining) at 7:23 a.m. \pm 45 minutes, near the acrophase for tritiated thymidine incorporation. We speculate that appropriately timed doses of the relevant chemotherapeutic agents, when topo II- $\alpha$ expression and S phase are minimal, might reduce the mucositis side effects. However, other factors such as the circadian rhythms in the drug clearance rate and in the tumor sensitivity must also be considered. Further work is needed to directly study these issues.

Acknowledgment: The authors thank Mr. ChienFwu Huang for subject recruitment and study assistance, Mrs. Gail Snow for immunostaining, and Mrs. Sharon Henn for manuscript preparation.

\section{REFERENCES}

1. Fisher LB. The diurnal mitotic rhythm in the human epidermis. Br J Dermatol 1968;80:75-80.
2. Scheving LE. Mitotic activity in the human epidermis. Anat Rec 1959;135:7-20.

3. Zugula-Mally ZW, Cardoso SS, Williams D, Simpson H, Reinberg A. Time point differences in skin mitotic activity of actinic keratoses and skin cancer. In: Reinberg A, Halberg F, editors. Chronopharmacology. New York: Pergamon; 1979. p. 399-402.

4. Bjarnason GA, Jordan RC, Sothern RB. Circadian variation in the expression of cell-cycle proteins in human oral epithelium. Am J Pathol 1999;154(2):613-22.

5. Buchi KN, Moore JG, Hrushesky WJ, Sothern RB, Rubin NH. Circadian rhythm of cellular proliferation in the human rectal mucosa. Gastroenterology 1991;101(2):410-5.

6. Marra G, Anti M, Percesepe A, Armelao F, Ficarelli R, Coco C, et al. Circadian variations of epithelial cell proliferation in human rectal crypts. Gastroenterology 1994;106(4):982-7.

7. Smaaland R, Laerum OD, Lote K, Sletvold O, Sothern RB, Bjerknes R. DNA synthesis in human bone marrow is circadian stage dependent. Blood 1991;77(12):2603-11.

8. Smaaland R, Sothern RB. Circadian cytokinetics of murine and human bone marrow and human cancer. In: Hrushesky WJM, editor. Circadian cancer therapy. Boca Raton, FL: CRC Press; 1994. p. 119-63.

9. Mormont MC, Boughattas N, Levi F. Mechanisms of circadian rhythms in the toxicity and efficacy of anticancer drugs: relevance for the development of new analogs. In: Lemmer B, editor. Chronopharmacology. New York: Marcel Dekker; 1989. p. 395-437.

10. Bjarneson GA, Hrushesky WJM. Cancer chemotherapy. In: Hrushesky WJM, editor. Circadian cancer therapy. Boca Raton, FL: CRC Press; 1994. p. 241-63.

11. Levi F, Zidani R, Misset JL. Randomised multicentre trial of chronotherapy with oxaliplatin, fluorouracil, and folinic acid in metastatic colorectal cancer. International Organization for Cancer Chronotherapy. Lancet 1997;350(9079):681-6.

12. Levi FA, Zidani R, Vannetzel JM, Perpoint B, Focan C, Faggiuolo $\mathrm{R}$, et al. Chronomodulated versus fixed-infusion-rate delivery of ambulatory chemotherapy with oxaliplatin, fluorouracil, and folinic acid (leucovorin) in patients with colorectal cancer metastases: a randomized multi-institutional trial. J Natl Cancer Inst 1994;86(21):1608-17.

13. Levi F, Zidani R, Brienza S, Dogliotti L, Perpoint B, Rotarski M, et al. A multicenter evaluation of intensified, ambulatory, chronomodulated chemotherapy with oxaliplatin, 5-fluorouracil, and leucovorin as initial treatment of patients with metastatic colorectal carcinoma. International Organization for Cancer Chronotherapy. Cancer 1999;85(12):2532-40.

14. Wang JC. DNA topoisomerases. Annu Rev Biochem 1996;65: 635-92.

15. Adachi Y, Luke M, Laemmli UK. Chromosome assembly in vitro: topoisomerase II is required for condensation. Cell 1991;64(1):137-48.

16. DiNardo S, Voelkel K, Sternglanz R. DNA topoisomerase II mutant of Saccharomyces cerevisiae: topoisomerase II is required for segregation of daughter molecules at the termination of DNA replication. Proc Natl Acad Sci U S A 1984; 81(9):2616-20.

17. Holm C, Stearns T, Botstein D. DNA topoisomerase II must act at mitosis to prevent nondisjunction and chromosome breakage. Mol Cell Biol 1989;9(1):159-68.

18. Heck MM, Hittelman WN, Earnshaw WC. Differential expression of DNA topoisomerases I and II during the eukaryotic cell cycle. Proc Natl Acad Sci USA 1988;85:1086-90.

19. Woessner RD, Mattern MR, Mirabelli CK, Johnson RK, Drake FH. Proliferation- and cell cycle-dependent differences in expression of the 170 kilodalton and 180 kilodalton forms of topoisomerase II in NIH- 3T3 cells. Cell Growth Differ 1991; 2(4):209-14. 
20. Holden JA. Human deoxyribonucleic acid topoisomerases: molecular targets of anticancer drugs. Ann Clin Lab Sci 1997;27(6):402-12.

21. Corbett AH, Osheroff N. When good enzymes go bad: conversion of topoisomerase II to a cellular toxin by antineoplastic drugs. Chem Res Toxicol 1993;6(5):585-97.

22. Nitiss JL, Wang JC. Mechanisms of cell killing by drugs that trap covalent complexes between DNA topoisomerases and DNA. Mol Pharmacol 1996;50(5):1095-102.

23. Ohdo S, Makinosumi T, Ishizaki T, Yukawa E, Higuchi S, Nakano S, et al. Cell cycle-dependent chronotoxicity of irinotecan hydrochloride in mice. J Pharmacol Exp Ther 1997; 283(3):1383-8.

24. Holden JA, Townsend JJ. DNA topoisomerase II-alpha as a proliferation marker in astrocytic neoplasms of the central nervous system: correlation with MIB1 expression and patient survival. Mod Pathol 1999;12(12):1094-100.

25. Mojon A, Fernandez JR, Hermida RC. Chronolab: an interactive software package for chronobiologic time series analysis written for the Macintosh computer. Chronobiol Int 1992;9:302-12.

26. Sothern RB, Voegelen M, Mattson O, Hrushesky WJM. A chronobiological Statistical Package for Personal Computer. Chronobiologica 1989;16:184.

27. Bauman ME, Holden JA, Brown KA, Harker WG, Perkins SL. Differential immunohistochemical staining for DNA topoisomerase II alpha and beta in human tissues and for DNA topoisomerase II beta in non-Hodgkin's lymphomas. Mod Pathol 1997;10(3):168-75.

28. Maurer HR. Potential pitfalls of $[3 \mathrm{H}]$ thymidine techniques to measure cell proliferation. Cell Tissue Kinet 1981;14(2):11120.

29. Bjarnason GA, Jordan RC, Wood PA, Li Q, Lincoln DW, Sothern RB, et al. Circadian expression of clock genes in human oral mucosa and skin: association with specific cellcycle phases. Am J Pathol 2001;158(5):1793-801.

30. Scheving LE, Burns ER, Pauly JE, Tsai TH. Circadian variation in cell division of the mouse alimentary tract, bone marrow and corneal epithelium. Anat Rec 1978;191(4):47986.

31. Hrushesky WJ. Circadian timing of cancer chemotherapy. Science 1985;228(4695):73-5.

32. Kobayashi M, Wood PA, Hrushesky WJ. Circadian chemotherapy for gynecological and genitourinary cancers. Chronobiol Int 2002;19(1):237-51.

33. Barrett RJ, Blessing JA, Homesley HD, Twiggs L, Webster KD. Circadian-timed combination doxorubicin-cisplatin chemotherapy for advanced endometrial carcinoma. A phase II study of the Gynecologic Oncology Group. Am J Clin Oncol 1993;16(6):494-6.

34. Canal P, Sqall A, de Forni M, Chevreau C, Pujol A, Bugat R, et al. Chronopharmacokinetics of doxorubicin in patients with breast cancer. Eur J Clin Pharmacol 1991;40(3):287-91.

35. Eksborg S, Stendahl U, Antila K. Pharmacokinetics of 4' epi-adriamycin after morning and afternoon intravenous administration. Med Oncol Tumor Pharmacother 1989;6(3): $195-7$.

36. Minami H, Ratain MJ, Ando Y, Shimokata K. Pharmacodynamic modeling of prolonged administration of etoposide. Cancer Chemother Pharmacol 1996;39(1-2):61-6.

37. Kuhl JFW, Grage TB, Halberg F, Rosene G, Scheving L, Haus E. Ellen-effect. Tolerance of adriamycin by Bagg albino mice and Fisher rats depends on circadian timing of injection. Int J Chronobiol 1973;1(1):335.

38. Peleg L, Ashkenazi IE, Carlebach R, Chaitchik S. Timedependent toxicity of drugs used in cancer chemotherapy: separate and combined administration. Int J Cancer 1989; 44(2):273-5.

39. Levi F, Halberg F, Haus E, Sanchez de la Pena S, Sothern RB, Halberg E, et al. Synthetic adrenocorticotropin for optimizing murine circadian chronotolerance for adriamycin. Chronobiologia 1980;7(2):227-44.

40. Granda TG, Filipski E, D'Attino RM, Vrignaud P, Anjo A, Bissery MC, et al. Experimental chronotherapy of mouse mammary adenocarcinoma MA13/C with docetaxel and doxorubicin as single agents and in combination. Cancer Res 2001;61(5):1996-2001.

41. Davies GJ, Macdonald J, Halberg F, Simpson HW. Circadian rhythm in murine tolerance of daunorubicin [letter]. Lancet 1974;2(7883):779.

42. Levi F, Mechkouri M, Roulon A, Bailleul F, Lemaigre G, Reinberg A, et al. Circadian rhythm in tolerance of mice for the new anthracycline analog 4'-O-tetrahydropyranyl-adriamycin (THP). Eur J Cancer Clin Oncol 1985;21(10):1245-51.

43. Levi F, Blazsek I, Ferle-Vidovic A. Circadian and seasonal rhythms in murine bone marrow colony-forming cells affect tolerance for the anticancer agent 4'-O-tetrahydropyranyladriamycin (THP). Exp Hematol 1988;16(8):696-701.

44. Mormont MC, von Roemeling R, Sothern RB, Berestka JS, Langevin TR, Wick M, et al. Circadian rhythm and seasonal dependence in the toxicological response of mice to epirubicin. Invest New Drugs 1988;6(4):273-83.

45. Levi F, Mechkouri M, Roulon A, Bailleul F, Horvath C, Reinberg A, et al. Circadian rhythm in tolerance of mice for etoposide. Cancer Treat Rep 1985;69(12):1443-5. 